BNL-112539-2016-JA

File \# 93471

\title{
Effect of Ni Content on the Morphological Evolution of Ni-YSZ Solid Oxide Fuel Cell Electrodes
}

\author{
Yu-chen Karen Chen-Wiegart, David Kennouche, \\ J. Scott Cronin, Scott A. Barnett, Jun Wang
}

Submitted to Applied Physics Letters

February 2016

Photon Sciences Department

Brookhaven National Laboratory

\author{
U.S. Department of Energy \\ USDOE Office of Science (SC), \\ Basic Energy Sciences (BES) (SC-22)
}

Notice: This manuscript has been authored by employees of Brookhaven Science Associates, LLC under Contract No. DE- SC0012704 with the U.S. Department of Energy. The publisher by accepting the manuscript for publication acknowledges that the United States Government retains a non-exclusive, paid-up, irrevocable, world-wide license to publish or reproduce the published form of this manuscript, or allow others to do so, for United States Government purposes. 


\section{DISCLAIMER}

This report was prepared as an account of work sponsored by an agency of the United States Government. Neither the United States Government nor any agency thereof, nor any of their employees, nor any of their contractors, subcontractors, or their employees, makes any warranty, express or implied, or assumes any legal liability or responsibility for the accuracy, completeness, or any third party's use or the results of such use of any information, apparatus, product, or process disclosed, or represents that its use would not infringe privately owned rights. Reference herein to any specific commercial product, process, or service by trade name, trademark, manufacturer, or otherwise, does not necessarily constitute or imply its endorsement, recommendation, or favoring by the United States Government or any agency thereof or its contractors or subcontractors. The views and opinions of authors expressed herein do not necessarily state or reflect those of the United States Government or any agency thereof. 
BNL-112539-2016-JA

File \# 93471

\title{
Effect of Ni Content on the Morphological Evolution of Ni-YSZ Solid Oxide Fuel Cell Electrodes
}

Authors:

Yu-chen Karen Chen-Wiegart ${ }^{1}$, David Kennouche ${ }^{2}$, J. Scott Cronin ${ }^{2}$, Scott A. Barnett ${ }^{2}$, Jun Wang $^{1}$

${ }^{1}$ National Synchrotron Light Source II, Brookhaven National Laboratory, 744 Ring Road, Upton, NY, 11973, USA

${ }^{2}$ Department of Materials Science and Engineering, Northwestern University, 2220 Campus Drive, Evanston, IL, 60208, USA

* Corresponding author. Email: junwang@bnl.gov, phone: +1-631-344-2661, fax: +1-631-344-3238

\begin{abstract}
The coarsening of $\mathrm{Ni}$ in $\mathrm{Ni}$ - yttria-stabilized zirconia (YSZ) anodes is a potential cause of long term SOFC performance degradation. The specifics of the Ni-YSZ structure - including Ni/YSZ ratio, porosity, and particle size distributions - are normally selected to minimize anode polarization resistance, but they also impact long-term stability. A better understanding of how these factors influence long-term stability is important for designing more durable anodes. The effect of structural details, e.g. Ni-YSZ ratio, on Ni coarsening has not been quantified. Furthermore, prior measurements have been done by comparing evolved structures with control samples, such that sample-to-sample variations introduce errors. Here we report a 4D (three spatial dimensions and time) study of Ni coarsening in Ni-YSZ anode functional layers with different Ni/YSZ ratios, using synchrotron x-ray nano-tomography. The continuous structural evolution was observed and analyzed at sub-100 nm resolution. It is shown quantitatively that increasing the Ni/YSZ ratio increases the Ni coarsening rate. This is due to both increased pore volume and a decrease in the YSZ volume fraction, such that there is more free volume and a less obtrusive YSZ network, both of which allow greater Ni coarsening. The results are shown to be in good agreement with a power-law coarsening model. The finding is critical for informing the design of SOFC electrode microstructures that limit coarsening and performance degradation.
\end{abstract}




\section{Text}

Solid oxide fuel cells (SOFC) are modular, scalable, and can yield efficiency up to $60 \%,{ }^{1}$. and are therefore ideal energy conversion devices for environmentally friendly large scale power plants ${ }^{2}$. They are fuel-flexible - SOFCs can reform methane internally and can use carbon monoxide as a fuel ${ }^{3}$. In addition, a reversible form of SOFC - solid oxide electrolysis cells -has potential for large-scale energy storage, carbon capture and chemical synthesis. ${ }^{4}$

One of the key issues that has limited commercial adoption of SOFCs is long-term durability. 5 . The elevated operating temperature can help give rise to cell performance degradation via various mechanisms including microstructural changes, reaction between cathode and electrolyte materials, poisoning, and mechanical instability such as cracking ${ }^{6,7}$ Coarsening of $\mathrm{Ni}$ in the NiYSZ anode, which results in a decrease in the density of electrochemically active three-phase boundaries, has been widely cited as an important degradation mechanism ${ }^{6}$ 8-10 $\mathrm{Ni}$ coarsening can also compromise the connectivity of the Ni network, leading to a significant decrease in electrical conductivity ${ }^{10}$.

Scanning electron microscope (SEM) cross-sectional imaging has been used extensively to observe Ni coarsening in Ni-YSZ anodes at elevated temperature ${ }^{6,11}$. Ni-YSZ anode structures can vary greatly depending on Ni/YSZ ratio, pore fraction, and particle size distributions, $\mathrm{NiO}$ reduction temperature, and fuel humidity. 12, 13 Recently, three-dimensional (3D) characterization methods including focused-ion-beam serial sectioning and x-ray nanotomography have been used to quantitatively determine the effect of Ni-YSZ morphology, including Ni content, on electrochemical characteristics. ${ }^{14,15} 16,17$ On the other hand, there have been few studies exploring effects of microstructural factors on long-term morphological stability and associated electrochemical degradation. Holzer et al. revealed that in Ni-GDC system, higher $\mathrm{Ni}$ volume fractions leads to higher coarsening and degradation rate ${ }^{13}$. Furthermore, prior degradation studies were carried out by comparing averaged microstructural quantities from anodes that were subjected to varying ageing treatments. As a result, it was not possible to observe how specific morphological features evolved, and sample-to-sample variations led to increased experimental errors. While x-ray tomographic measurements are nondestructive and hence have the potential to repeatedly measure the same anode microstructure, the few reports of such measurements on Ni-YSZ were only to observe limited morphological changes during relatively short low temperature heat treatments. ${ }^{18,19}$.

In this work, we developed and carried out an x-ray nano-tomography measurement with sub-100 nm resolution to directly observe the morphological evolution of a Ni-YSZ anode. In these experiments, alternating x-ray nano-tomography measurements and iso-thermal heat treatments in a typical humidified hydrogen fuel were carried out. The experiments were done with two anodes with different Ni volumetric fractions, 65:35 wt\% and 50:50 wt\% NiO:YSZ, in order to directly probe the effect of $\mathrm{Ni}$ content. The results are explained using a particle coarsening model. 
First, anode-supported button cell was prepared for this study with starting powders of J.T. Baker $\mathrm{NiO}$ and Tosoh $\mathrm{Zr}_{0.84} \mathrm{Y}_{0.16} \mathrm{O}_{2-\delta}$ (YSZ) and both were ball-milled. To increase structure porosity and green-body strength, additives of $10 \mathrm{wt}$. \% tapioca starch (Erawan) and $1 \mathrm{wt}$ \% Aldrich PVB were included in the ball milling. The solution was then dried, ground, and sieved through a 325 mesh. The resulting powders were then uniaxially pressed in a $3 / 4$ " die and bisque fired at $1060^{\circ} \mathrm{C}$ for 4 hrs. Two different NiO/YSZ ratio - colloidal solution of 65:35 wt $\%$ NiO:YSZ (Sample 65:35) and 50:50 wt\% NiO:YSZ (Sample 50:50) were deposited as anode functional layers in order to study the effect of YSZ on Ni coarsening. The 65:35 anode had Ni volume fraction $37 \%$ and YSZ volume fractions $40 \%$ after reduction ${ }^{15}$ compared to $28 \% \mathrm{Ni}$ and $53 \%$ YSZ for the 50:50 anode $^{20}$. Pure YSZ were then deposited on the support to form the electrolyte layer. After sintering the sample at $1400^{\circ} \mathrm{C}$ for $4 \mathrm{~h}$, a $\sim 20 \mu \mathrm{m}$ anode functional layer and fully dense $\sim 10 \mu \mathrm{m}$ electrolyte layer were formed, respectively.

The in situ nano-tomography experiments were carried out at beamline $\mathrm{X} 8 \mathrm{C}$, transmission $\mathrm{X}$ ray microscopy beamline at National Synchrotron Light Source. The microscope has been demonstrated with a sub-30 nm 2D resolution and sub-50 nm 3D resolution. ${ }^{21}$. An as-prepared sample was then carefully cut by diamond saw to result in a wedge-shape sharp corner of the anode materials, with a diameter around $40 \mu \mathrm{m}$ to allow x-ray nano-tomography experiment. A total of 1441 projections were collected for each tomography dataset, by rotating the sample over an angular range of $180^{\circ}$, with a step size of $0.125^{\circ}$. Two sets of tomography measurements were carried out for each heat treatment time point: one just above the Ni absorption K-edge for best contrast of the Ni phase and one just below for the best contrast between the pore and the solid (YSZ and Ni) phases. The heat treatment of the sample was alternated with the tomography experiment. Annealing experiment was carried out in the tube furnace with humidified hydrogen flow at $1050^{\circ} \mathrm{C}$ to simulate the reduction environment. The annealing time was prolonged after each tomography, resulting a total annealing time on the same sample at 0, 12, 24, 48, and $92 \mathrm{hr}$.

The morphological analysis was then carried out on the tomographic data. The reconstruction of the tomography was performed by standard filtered-back-projection algorithm. The full reconstructed volume is a cylinder with $40 \mu \mathrm{m}$ diameter and height. The $3 \mathrm{D}$ morphological evolution of the 65:35 anode from x-ray nano-tomography at different times is shown as 2D pseudo cross-sectional images in Figure 1 (A) and 3D volume rendering in Figure 1 (B). Pronounced Ni coarsening was observed at the sample free surfaces within the first 12-24 hr; the Ni particles agglomerated and developed into facetted particles with increasing time (shown as arrows in Figure 1). This extreme coarsening is an artifact in the sense that a real Ni-YSZ anode functional layer has no free surfaces, except at cell edges that are far from the electrochemically active area. Thus, only the central region of the sample, at a distance $>\sim 5 \mu \mathrm{m}$ from the surfaces, is discussed in the remainder of this paper. As shown below, the Ni content in this volume does not change with annealing, indicating that the surface coarsening did not significantly impact the internal region, and hence it is truly representative of the coarsening in an actual SOFC. It is clear from visual inspection that the internal portion of the $\mathrm{Ni}$ also coarsens, but at a much slower 
rate. This difference in the internal and free-surface coarsening rates clearly illustrates the important role of the YSZ phase in constraining the Ni coarsening.

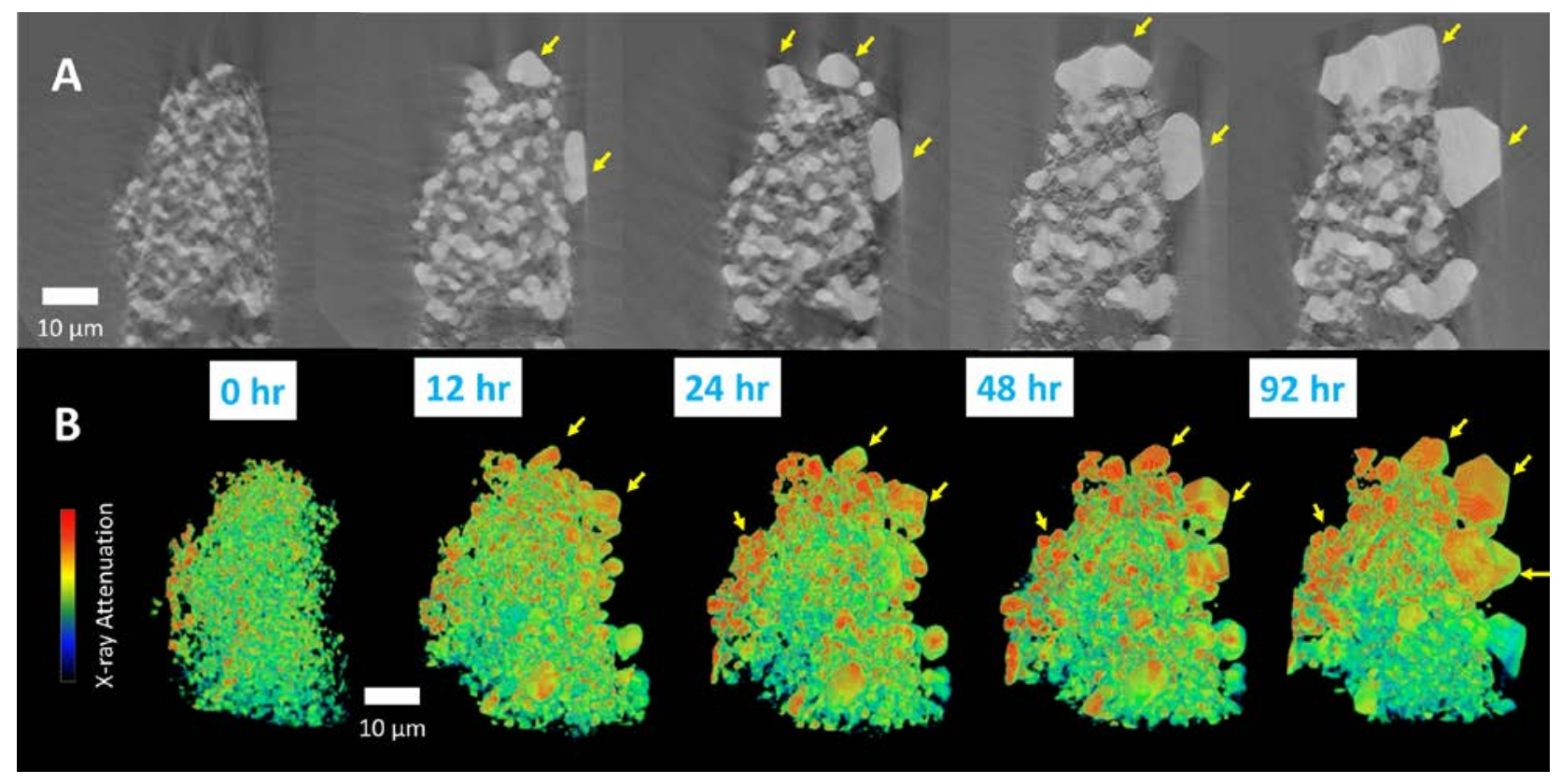

Figure 1 - (A) Pseudo cross-sectional 2D images and (B) 3D volume renderings taken after different ageing times at $1050{ }^{\circ} \mathrm{C}$, showing the morphological evolution of the 65:35 Ni-YSZ anode. Arrows indicate the rapid coarsening and faceting of the surface free Ni particles.

The internal portions of the imaged anode volumes were cropped and analyzed, avoiding the excessive coarsening at the surfaces. The cropped volume of interest was $13.6 \times 17.5 \times 6.3$ $\mu^{3}$ from 65-36 sample and $26.2 \times 8.6 \times 9.0 \mu^{3}$ from 50-50 sample, approximately 2-8 microns away from the highly coarsened surface regions. The volume size presented in this work is within the reasonable range of sample volume presented in the field ${ }^{15,19,22}$. The segmentation of $\mathrm{Ni}$ was then performed by thresholding method of the above-edge data where the Ni and the other phases can be separated by selecting the minimum of the gray-scale histogram as the threshold value. The volume fraction measurement as described later, was found to agree with the expected Ni volume fraction value and therefore provides a validation of the accuracy of the thresholding segmentation. It also provides a cross-check to ensure that the central cropped region is indeed representative to discuss the properties of the materials. The Ni data were segmented for all data points to investigate the Ni coarsening quantitatively. The pore phase was segmented by thresholding the below-edge data where the pore and the solid phases have sufficient contrast. This was performed as needed for visualization. It should be noted that the data quality was not sufficient to provide accurate measurement of parameters that are highly sensitive to surface and small features, such as triple phase boundary (TPB) density due to the image quality of pore and YSZ phase. However, it is sufficient to provide information such as 
particle size distribution, especially for the Ni phase. It should also be noted that we cannot discuss the YSZ morphology for the same reason. The data quality can be further improved by advancing the sample preparation methods in order to provide information such as YSZ morphology and TPB density. After segmentation, several quantification of the Ni phase as the function of time was then performed, including the volume fraction and particle size distribution (PSD) ${ }^{23}$. A PSD of the Ni and pore phase combined was also carried out in order to calculate $\left(D_{N i-\max }\right)$. A 3D volume registration algorithm was performed to enable tracking the evolution of the same region of the structure continuously. The analysis was carried out using a combination of commercial package Avizo (FEI), Matlab (Mathworks) programs developed in-house, and freeware FIJI.

The Ni volume fractions of the cropped central regions from the 65:35 and 50:50 anodes are shown in Figure 2(A). Note that the Ni volume fraction does not change with ageing time, within measurement accuracy, despite the surface Ni agglomeration. Furthermore, the measured $\mathrm{Ni}$ volume fraction of both anode compositions agrees well with prior measurements of identically processed anodes. ${ }^{15,17}$ Thus, the Ni content in the internal regions was not decreased by the Ni surface agglomeration, such that the cropped volume should accurately represent the typical coarsening behavior in an operational SOFC anode.

Figure 2(B) shows the Ni average feature size as a function of the coarsening time in both the 65-35 and 50-50 anodes, obtained from the individual size distributions shown in Figure 2(CD). Over the 92 hours of accelerated high temperature annealing at $1050^{\circ} \mathrm{C}$, the Ni size in the 6535 sample increased by nearly a factor of two, from 495 to $865 \mathrm{~nm}$. On the contrary, the Ni in the 5050 sample increased by $<10 \%$, barely significant above the measurement accuracy, from 375 to $410 \mathrm{~nm}$. This trend is also evident in the size distribution shown in Figure 2(C-D) for 65-35 sample and 50-50 sample, respectively, where little change in the size distribution was found in the 50-50 sample. The larger initial average Ni size in the 65:35 anode presumably results from the increased opportunities for $\mathrm{NiO}-\mathrm{NiO}$ particle sintering during the high-temperature firing of the higher-NiO-content anode. It is especially notable that the coarsening rate is faster for larger starting Ni feature size, since coarsening usually slows with increasing size. 

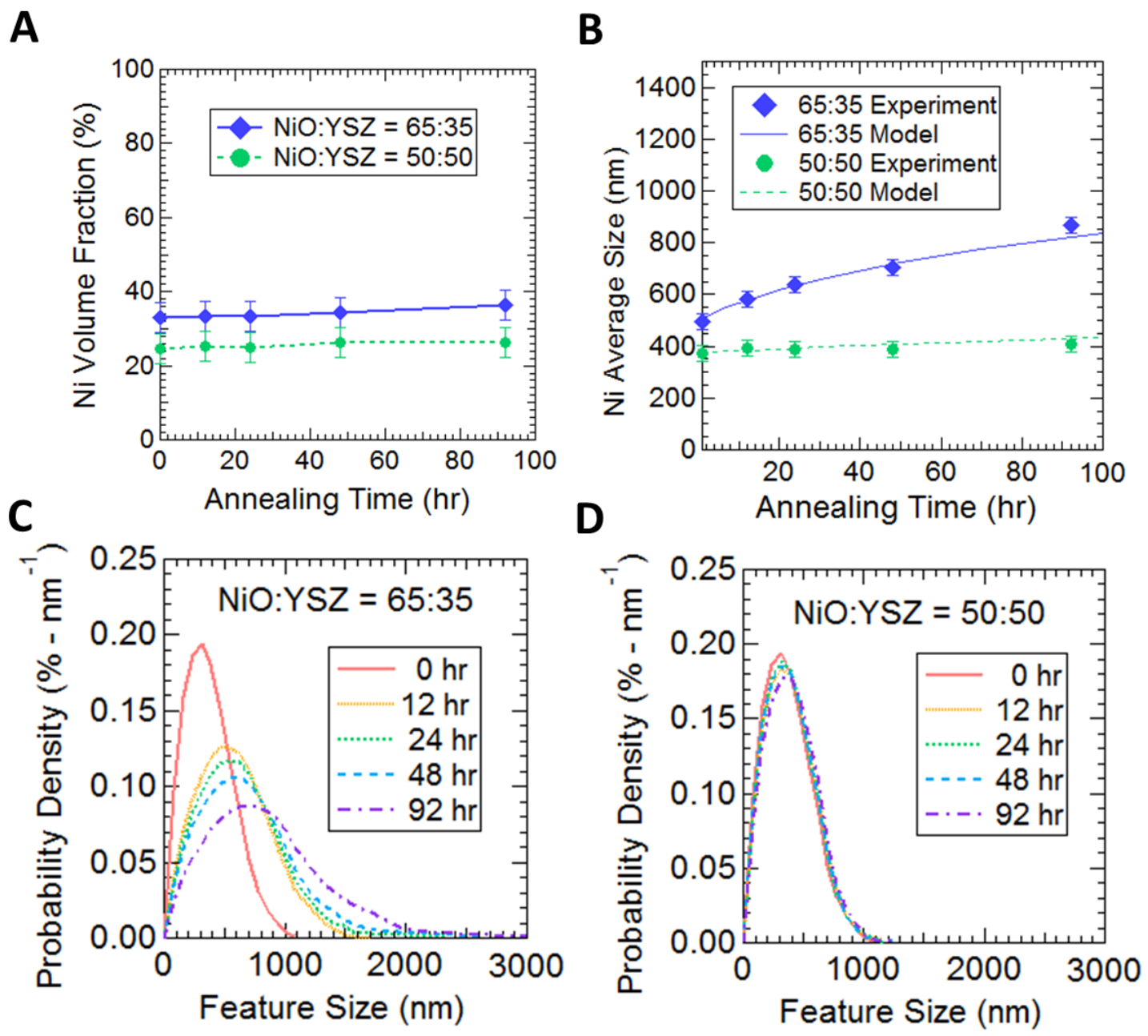

Figure 2 -_(A) Volume fraction of the Ni phase versus aging time, (B) Ni average size versus aging time, and Ni feature size distributions for two different anodes: (C) NiO:YSZ = 65:35 and (D) $\mathrm{NiO}: \mathrm{YSZ}=50: 50$

Figure 3 and Figure 4 show reconstructed image views of the cropped volumes of the 65-35 and 50:50 anodes at different times. Again, the larger starting size and greater particle size growth in the 65:35 anode is evident. The 'zoomed-in' views of the selected regions can be seen in Figure 3 (B) and (D). For 65:35 sample, as seen in Figure 3 (B), it is observed that 1) some smaller Ni structures disappear, while 2) some larger Ni clusters continues to coarsen, highlighted as the circled regions in Figure 3(B). Such changes are expected results of particle coalescence and Ostwald ripening. During this process, the Ni surface area decreases and therefore reduces the overall surface energy. Overall, the reaction points, triple phase boundaries, inevitably decrease as a result of the $\mathrm{Ni}$ coarsening. On the contrary, the 50:50 sample shows relatively little morphological variation during the course of the heat treatment, as can be seen in the Figure 4. One change that can be observed is the coalescence of two initially separate Ni particles [circled in Figure 4 (B)] 


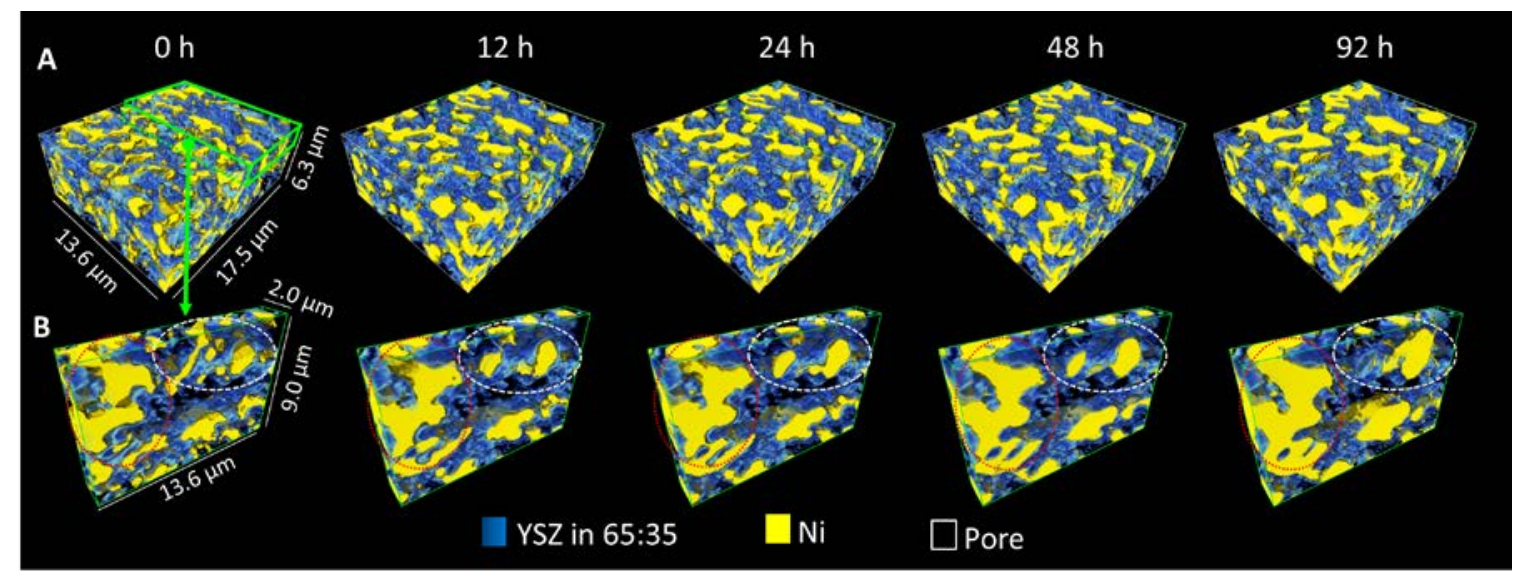

Figure 3 - 3D analyzed volumes from 65:35 sample of different heat treatment time: (A) entire analyzed volume and (B) 'zoomed-in' views. Note that the pore/YSZ structure view is to provide visual guideline here.

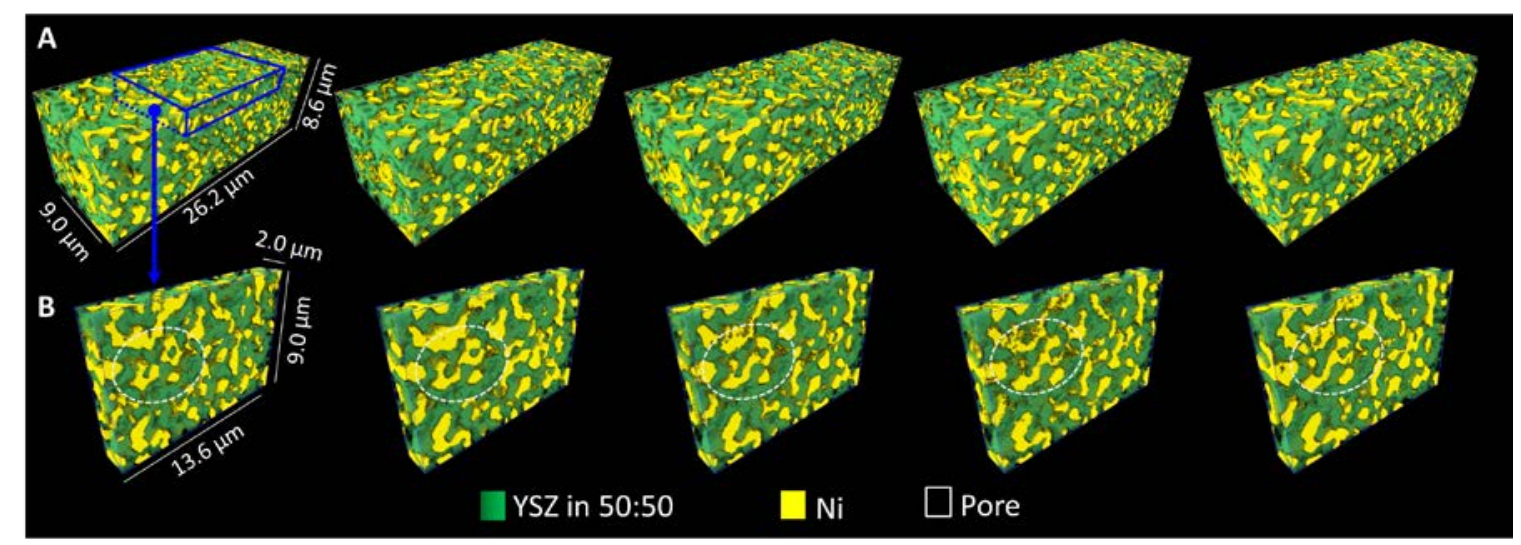

Figure 4 - 3D analyzed volumes from 50:50 sample of different heat treatment time: (A) entire analyzed volume and (B) 'zoomed-in' views. Note that the pore/YSZ structure view is to provide visual guideline here.

The feature size changes shown in Figure 2(B) were explained based on a standard power-law coarsening model ${ }^{24}$ where the relationship between the characteristic length (l) and the coarsening time $(t)$ can be described by the following equation:

$l^{n}-l_{0}^{n}=K_{D} t-(1)$

Here, $l_{0}$ is the initial characteristic length, $K_{D}$ is the mass transport coefficient, and $n$ is a transport mechanism-dependent coefficient. $K_{D}$ can be written in the following form:

$K_{D}=K_{D, 0} \exp \left(-E_{A} / k T\right)$ 
where $E_{A}$ is the activation energy depending on coarsening mechanism, $k$ is the Boltzmann constant, $T$ is the temperature ${ }^{25}$. Combining equations (1) and (2), the characteristic length and coarsening time can be described as:

$\left.l=\left[l_{0}+K_{D, 0} t \exp \left(-E_{A} / k T\right)\right)\right]^{1 / 4}$

In a recent study of 50:50 Ni-YSZ anodes, this power-law coarsening expression was used with $\mathrm{E}_{\mathrm{D}}=2.65 \mathrm{eV}, \mathrm{K}_{\mathrm{D}, 0}=1.59 \times 10^{-28} \mathrm{~m}^{4} \mathrm{~s}^{-1}$, and $\mathrm{n}=4$ to fit to 3D data for ageing at different temperatures and times. ${ }^{26} \mathrm{n}=4$ is expected when surface diffusion is the dominant transport mechanism. Bulk diffusion is expected to be slow compared to the surface diffusion., whereas vapor transport is not expected to be important at the relatively low steam partial pressure used here ${ }^{27}$. The curve shown in Figure 2(B) for the 50:50 anode, calculated using equation (3) with the values given above, shows almost no coarsening for these conditions, in agreement with the present data. That is, the present 50:50 anode results are consistent with prior results on similar anodes. ${ }^{26}$

Although the data for the 65:35 anode shows much faster coarsening, it can also be fit very well using the same expression by increasing $K_{D}$ by a factor of 27 relative to the 50:50 anode, as shown in Figure 2(B). The basic transport process, e.g. Ni surface diffusion, presumably does not change and hence $E_{D}$ should be the same. However, the different anode morphology - greater Ni content, shorter diffusion lengths due to lesser YSZ content, and more available empty sites due to higher pore volume, can be expected to increase $\mathrm{K}_{\mathrm{D}, 0}$. The fitting parameters are summarized in Table 1.

\begin{tabular}{|l|l|l|}
\hline & $E_{A}(\mathrm{eV})$ & $K_{D}\left(\mathrm{~m}^{4} \cdot \mathrm{s}^{-1}\right)$ at $1050^{\circ} \mathrm{C}$ \\
\hline Ni in 50:50 & 2.65 & $1.59 \mathrm{E}-28$ \\
\hline Ni in 65:35 & 2.28 & $4.26 \mathrm{E}-27$ \\
\hline
\end{tabular}

Table 1 - Surface diffusion activation energy $E_{A}$ and mass transport coeficienet $K_{D}$ associated with both samples.

The YSZ constraining effect shown here suggests that the coarsening of Ni would depend on the nature of the interface between Ni and YSZ. More generally, interface properties between the metallic phase and the electrolyte phase shall be considered for optimal SOFC performance. This is consistent with theoretical and simulation work in the literatures, where the importance of the wettability and contact angle between $\mathrm{Ni}$ and $\mathrm{YSZ}^{28}$, adhesion of Ni to different types of ceramic electrolytes ${ }^{29}$, interfacial energy between Ni and YSZ, and contact angle of the electrochemically active triple- phase boundaries (TPBs) ${ }^{9}$ have been considered. For instance, the work from Davis et al. shows the direct effect of contact angle to the performancedetermining morphological properties such as the density of active TPBs and the contiguity of the electron-conducting phase. ${ }^{28}$ 
In conclusion, we have demonstrated an in situ experiment where the 3D morphological evolution of the same solid oxide fuel cell anode was observed repeatedly and its coarsening behavior was quantified. We show that the YSZ plays an important role in constraining $\mathrm{Ni}$ coarsening in Ni-YSZ, and that reducing the amount of YSZ allows more rapid Ni coarsening. The Ni phase in the higher-YSZ-content anode (NiO:YSZ = 50:50) increased its average size by $<10 \%$, significantly less than the lower-YSZ-content anode (NiO:YSZ = 65:35), which increased by nearly $100 \%$. The power law model shows good fit with the experimental data; higher Ni diffusivity in the 65:35 sample, due to reduced constraint by the reduced amount of YSZ, can quantitatively explain the increased Ni coarsening.

\section{Acknowledgements}

Use of the National Synchrotron Light Source, Brookhaven National Laboratory, was supported by the U.S. Department of Energy, Office of Science, Office of Basic Energy Sciences, under Contract No. DE-AC02-98CH10886. Data analysis carried out at National Synchrotron

Light Source II, Brookhaven National Laboratory, was supported by the U.S. Department of Energy, Office of Science, Office of Basic Energy Sciences, under Contract No. DE-SC0012704. The authors at Northwestern University gratefully acknowledge financial support from National Science Foundation Ceramics program through grants DMR-0907639 and DMR-1506925.

\section{Reference}

1. Bedringas, K. W.; Ertesvag, I. S.; Byggstoyl, S.; Magnussen, B. F., Energy analysis of solid-oxide fuel-cell (SOFC) systems. Energy 1997, 22 (4), 403-412.

2. Singhal, S. C., Advances in solid oxide fuel cell technology. Solid State Ion. 2000, 135 (1-4), 305313; Yamamoto, O., Solid oxide fuel cells: fundamental aspects and prospects. Electrochim. Acta 2000, 45 (15-16), 2423-2435.

3. Wachsman, E. D.; Lee, K. T., Lowering the Temperature of Solid Oxide Fuel Cells. Science 2011, 334 (6058), 935-939; Hibino, T.; Hashimoto, A.; Inoue, T.; Tokuno, J.; Yoshida, S.; Sano, M., A lowoperating-temperature solid oxide fuel cell in hydrocarbon-air mixtures. Science 2000, 288 (5473), 20312033; Park, S. D.; Vohs, J. M.; Gorte, R. J., Direct oxidation of hydrocarbons in a solid-oxide fuel cell. Nature 2000, 404 (6775), 265-267. 
4. Laguna-Bercero, M. A., Recent advances in high temperature electrolysis using solid oxide fuel cells: A review. J. Power Sources 2012, 203, 4-16; Lessing, P. A., A review of sealing technologies applicable to solid oxide electrolysis cells. J. Mater. Sci. 2007, 42 (10), 3465-3476.

5. Sasaki, K.; Haga, K.; Yoshizumi, T.; Minematsu, D.; Yuki, E.; Liu, R. R.; Uryu, C.; Oshima, T.; Ogura, T.; Shiratori, Y.; Ito, K.; Koyama, M.; Yokomoto, K., Chemical durability of Solid Oxide Fuel Cells: Influence of impurities on long-term performance. J. Power Sources 2011, 196 (22), 9130-9140.

6. Tanasini, P.; Cannarozzo, M.; Costamagna, P.; Faes, A.; Van Herle, J.; Hessler-Wyser, A.; Comninellis, C., Experimental and Theoretical Investigation of Degradation Mechanisms by Particle Coarsening in SOFC Electrodes. Fuel Cells 2009, 9 (5), 740-752.

7. Abdeljawad, F.; Haataja, M., Microstructural coarsening effects on redox instability and mechanical damage in solid oxide fuel cell anodes. J. Appl. Phys. 2013, 114 (18); Shah, M.; Voorhees, P. W.; Barnett, S. A., Time-dependent performance changes in LSCF-infiltrated SOFC cathodes: The role of nano-particle coarsening. Solid State Ion. 2011, 187 (1), 64-67.

8. Abdeljawad, F.; Volker, B.; Davis, R.; McMeeking, R. M.; Haataja, M., Connecting microstructural coarsening processes to electrochemical performance in solid oxide fuel cells: An integrated modeling approach. J. Power Sources 2014, 250, 319-331.

9. Chen, H. Y.; Yu, H. C.; Cronin, J. S.; Wilson, J. R.; Barnett, S. A.; Thornton, K., Simulation of coarsening in three-phase solid oxide fuel cell anodes. Journal of Power Sources 2011, 196 (3), 13331337.

10. Simwonis, D.; Tietz, F.; Stover, D., Nickel coarsening in annealed Ni/8YSZ anode substrates for solid oxide fuel cells - In memoriam to Professor H. Tagawa. Solid State Ion. 2000, 132 (3-4), 241-251.

11. Faes, A.; Hessler-Wyser, A.; Presvytes, D.; Vayenas, C. G.; Van Herle, J., Nickel-Zirconia Anode Degradation and Triple Phase Boundary Quantification from Microstructural Analysis. Fuel Cells 2009, 9 (6), 841-851.

12. Prakash, B. S.; Kumar, S. S.; Aruna, S. T., Properties and development of Ni/YSZ as an anode material in solid oxide fuel cell: A review. Renewable \& Sustainable Energy Reviews 2014, 36, 149-179.

13. Holzer, L.; Iwanschitz, B.; Hocker, T.; Muench, B.; Prestat, M.; Wiedenmann, D.; Vogt, U.; Holtappels, P.; Sfeir, J.; Mai, A.; Graule, T., Microstructure degradation of cermet anodes for solid oxide fuel cells: Quantification of nickel grain growth in dry and in humid atmospheres. J. Power Sources 2011, 196 (3), 1279-1294.

14. Wilson, J. R.; Kobsiriphat, W.; Mendoza, R.; Chen, H. Y.; Hiller, J. M.; Miller, D. J.; Thornton, K.; Voorhees, P. W.; Adler, S. B.; Barnett, S. A., Three-dimensional reconstruction of a solid-oxide fuel-cell anode. Nature Materials 2006, 5 (7), 541-544; Nelson, G. J.; Harris, W. M.; Lombardo, J. J.; Izzo, J. R.; Chiu, W. K. S.; Tanasini, P.; Cantoni, M.; Van Herle, J.; Comninellis, C.; Andrews, J. C.; Liu, Y. J.; Pianetta, P.; Chu, Y. S., Comparison of SOFC cathode microstructure quantified using X-ray nanotomography and focused ion beam-scanning electron microscopy. Electrochemistry Communications 2011, 13 (6), 586 589.

15. Chen-Wiegart, Y. C. K.; Cronin, J. S.; Yuan, Q. X.; Yakal-Kremski, K. J.; Barnett, S. A.; Wang, J., 3D Non-destructive morphological analysis of a solid oxide fuel cell anode using full-field $X$-ray nanotomography. Journal of Power Sources 2012, 218, 348-351.

16. Wilson, J. R.; Cronin, J. S.; Duong, A. T.; Rukes, S.; Chen, H. Y.; Thornton, K.; Mumm, D. R.; Barnett, S., Effect of composition of ( $\mathrm{La}(0.8) \mathrm{Sr}(0.2) \mathrm{MnO}(3)-\mathrm{Y}(2) \mathrm{O}(3)$-stabilized $\mathrm{ZrO}(2))$ cathodes: Correlating three-dimensional microstructure and polarization resistance. J. Power Sources 2010, 195 (7), 1829-1840; Zhenjun, J.; Shikazono, N.; Kasagi, N., Quantitative Characterization of SOFC Nickel-YSZ Anode Microstructure Degradation Based on Focused-Ion-Beam 3D-Reconstruction Technique. Journal of the Electrochemical Society 2012, 159 (3), B285-91. 
17. Kennouche, D.; Chen-Wiegart, Y. C. K.; Cronin, J. S.; Wang, J.; Barnett, S. A., Three-Dimensional Microstructural Evolution of Ni-Yttria-Stabilized Zirconia Solid Oxide Fuel Cell Anodes At Elevated Temperatures. Journal of the Electrochemical Society 2013, 160 (11), F1293-F1304.

18. Shearing, P. R.; Bradley, R. S.; Gelb, J.; Lee, S. N.; Atkinson, A.; Withers, P. J.; Brandon, N. P., Using Synchrotron X-Ray Nano-CT to Characterize SOFC Electrode Microstructures in Three-Dimensions at Operating Temperature. Electrochemical and Solid State Letters 2011, 14 (10), B117-B120.

19. Shearing, P. R.; Bradley, R. S.; Gelb, J.; Tariq, F.; Withers, P. J.; Brandon, N. P., Exploring microstructural changes associated with oxidation in Ni-YSZ SOFC electrodes using high resolution $\mathrm{X}$-ray computed tomography. Solid State Ion. 2012, 216, 69-72.

20. Kennouche, D.; Chen-Wiegart, Y.-c. K.; Yakal-Kremski, K. J.; Wang, J.; Gibbs, J.; Voorhees, P.; Barnett, S. A., Observing the Microstructural Evolution of Ni- Yttria-Stabilized Zirconia Solid Oxide Fuel Cell

Anodes Acta Materialia (submitted) 2015.

21. Wang, J.; Chen, Y.-c. K.; Yuan, Q.; Tkachuk, A.; Erdonmez, C.; Hornberger, B.; Feser, M., Automated Markerless Full Field Hard X-ray Microscopic Tomography at Sub-50 nm 3D Spatial Resolution. Applied Physics Letters 2012, 100 (14), 143107-1-4.

22. Wilson, J. R.; Cronin, J. S.; Barnett, S. A., Linking the microstructure, performance and durability of Ni-yttria-stabilized zirconia solid oxide fuel cell anodes using three-dimensional focused ion beam scanning electron microscopy imaging. Scripta Materialia 2011, 65 (2), 67-72; Harris, W. M.; Lombardo, J. J.; DeGostin, M. B.; Nelson, G. J.; Luebbe, H.; Schuler, J. A.; Van Herle, J.; Andrews, J. C.; Liu, Y. J.; Pianetta, P.; Chen, Y. C. K.; Wang, J.; Chiu, W. K. S., Three-dimensional microstructural mapping of poisoning phases in the Neodymium Nickelate solid oxide fuel cell cathode. Solid State lonics 2013, 237, 16-21; Kennouche, D.; Chen-Wiegart, Y.-c. K.; Cronin, J. S.; Wang, J.; Barnett, S. A., Three-Dimensional Microstructural Evolution of Ni-Yttria-Stabilized Zirconia Solid Oxide Fuel Cell Anodes At Elevated Temperatures. Journal of the Electrochemical Society 2013, 160 (11), F1293-F1304; Yakal-Kremski, K.; Cronin, J. S.; Chen-Wiegart, Y. C. K.; Wang, J.; Barnett, S. A., Studies of Solid Oxide Fuel Cell Electrode Evolution Using 3D Tomography. Fuel Cells 2013, 13 (4), 449-454.

23. Holzer, L.; Munch, B.; Iwanschitz, B.; Cantoni, M.; Hocker, T.; Graule, T., Quantitative relationships between composition, particle size, triple phase boundary length and surface area in nickel-cermet anodes for Solid Oxide Fuel Cells. J. Power Sources 2011, 196 (17), 7076-7089.

24. Porter, D. A.; Easterling, K. E., Phase Transformations in Metals and Alloys. CRC Press, Taylor and Francis Group: Boca Raton, FL, USA, 2004 (Reprinted).

25. Chen-Wiegart, Y. C. K.; Wang, S.; Chu, Y. S.; Liu, W. J.; McNulty, I.; Voorhees, P. W.; Dunand, D. C., Structural evolution of nanoporous gold during thermal coarsening. Acta Materialia 2012, 60 (12), $4972-$ 4981.

26. Kennouche, D.; Chen-Wiegart, Y.-c. K.; Riscoe, C.; Wang, J.; Barnett, S. A., A Combined Electrochemical and X-ray Tomography Study of the High Temperature Evolution of Ni - Yttria Stabilized Zirconia Solid Oxide Fuel Cell Anodes. submitted 2015.

27. Hagen, A.; Barfod, R.; Hendriksen, P. V.; Liu, Y. L.; Ramousse, S., Degradation of anode supported SOFCs as a function of temperature and current load. Journal of the Electrochemical Society 2006, 153 (6), A1165-A1171.

28. Davis, R.; Abdeljawad, F.; Lillibridge, J.; Haataja, M., Phase wettability and microstructural evolution in solid oxide fuel cell anode materials. Acta Materialia 2014, 78, 271-281.

29. Xu, J.; Bai, S.; Higuchi, Y.; Ozawa, N.; Sato, K.; Hashida, T.; Kubo, M., Multi-nanoparticle model simulations of the porosity effect on sintering processes in Ni/YSZ and Ni/ScSZ by the molecular dynamics method. Journal of Materials Chemistry A 2015, 3 (43), 21518-21527. 